\title{
MODELAGEM COMPUTACIONAL DE PAINÉIS SOLARES EM AMBIENTES COMPUTACIONAIS: CONTRIBUIÇÃO NO CONTROLE DE ENERGIA PELO LADO DE DEMANDA.
}

\author{
Lucas da Silva Cardoso ${ }^{1}$; João Bosco Gertrudes ${ }^{2}$ \\ 1. Bolsista PROBIC/UEFS, Graduando em Engenharia da Computação, Universidade Estadual de Feira de Santana, \\ e-mail: thelucascardoso@gmail.com \\ 2. Orientador, Departamento de Tecnologia, Universidade Estadual de Feira de Santana, e-mail: \\ jbosco@ecomp.uefs.br
}

PALAVRAS-CHAVE: mppt; geração solar; modelagem computacional.

\section{INTRODUÇÃO}

Nos dias atuais a demanda pela geração e consumo de energia elétrica chegam a patamares antes inimagináveis, e os sistemas clássicos para a geração de energia com base nos recursos naturais: termoelétricas, hidrelétricas, já não conseguem suprir tão satisfatoriamente a quantidade de energia solicitada.

Associado ao crescente aumento da demanda de energia, a utilização de recursos naturais provoca a redução da sua abundância na natureza, recursos esses que são únicos ou demoram muitos anos para se reestabelecer. Com a aproximação de crises de recursos naturais, outros métodos de geração de energia são estudados, principalmente a geração sustentável, onde se possa gerar a energia necessária, sem nenhum, ou quase nenhum dano ao meio ambiente.

Nesse segmento de geração de energia sustentável, a geração solar tem recebido grande destaque, juntamente com a geração eólica, com a adoção de diversas políticas de incentivo financeiro e tecnológico voltadas para a disseminação dessas tecnologias. A geração solar recebe um pouco mais de atenção pois é a mais acessível, sendo possível os consumidores finais se tornarem os próprios produtores de energia.

Este trabalho consiste em estudar o funcionamento de um painel solar, fazer uma breve discussão sobre o potencial energético do Brasil e abordar alguns métodos existentes que possibilitam extrair todo o potencial dos painéis solares, de forma a otimizar a produção de energia do painel.

\section{MATERIAL E MÉTODOS OU METODOLOGIA (ou equivalente)}

A partir das equações de modelagem computacional descritas em VILLALVA (2010), um modelo baseado nessas literaturas foi implementado em um ambiente computacional as equações que descrevem o comportamento de uma célula solar fotovoltaica. A partir da construção da modelagem computacional, testes e simulações foram executadas afim de realizar a validação da modelagem, para isso foram utilizados os dados presentes na folha de informações (datasheets) de um painel solar.

Após a validação da modelagem, foi realizado um trabalho de implementação, testes e comparações entre o modelo desenvolvido e um elemento que simula um painel solar disponibilizado pelo módulo Simscape Power Systems, que é associado aos softwares MatLab e Simulink. Foram analisados também dados referentes à capacidade de irradiância solar do Brasil em comparação a grandes produtores como a Alemanha.

Por fim foi estudado um dos métodos existente na literatura para a otimização do funcionamento dos painéis solares, métodos que buscam extrair a máxima potência dos equipamentos, método chamado Maximum Power Point Tracker (MPPT). 


\section{RESULTADOS E/OU DISCUSSÃO (ou Análise e discussão dos resultados)}

Encontrou-se nas literaturas duas formas de representar o funcionamento de um painel solar por equações matemáticas: a forma ideal e a forma mais realista. A forma mais realista leva em consideração valores de resistência em série e paralelo que constituem o painel solar e muitas vezes são ignoradas nas literaturas.

As equações de modelagem da célula fotovoltaica foram implementadas no software MatLab, software bem conhecido e presente em diversas literaturas. Após a implementação das equações foram feitas validações do algoritmo utilizando as informações presentes no datasheet fornecido pelos fabricantes, conseguiu-se perceber que a representação mais realista do painel solar conseguiu reproduzir resultados muito próximo aos resultados do datasheet do fabricante, como podemos observar nas figuras abaixo:
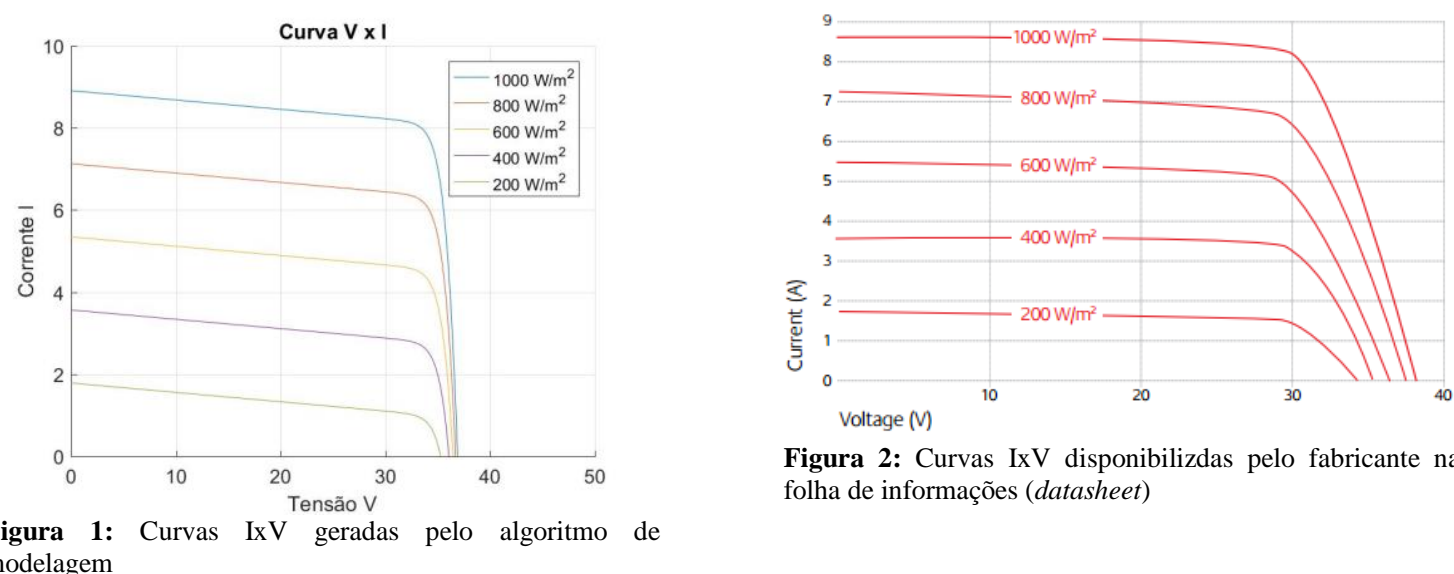

Figura 2: Curvas IxV disponibilizdas pelo fabricante na folha de informações (datasheet)

Finalizado este processo de teste do modelo, realizou-se uma comparação entre o modelo desenvolvido e um elemento que simula um painel solar disponibilizado pelo módulo Simscape Power Systems no Simulink, chamado de PV Array o elemnto possui uma biblioteca de dados de diversos fabricantes, incluindo os dados do painel solar utilizado para a validação do modelo desenvolvido, com base nesses dados foi executada uma simulação que como resultado obtivemos curvas condizentes com o datasheet e com o modelo desenvolvido, demonstrando assim uma equivalência entre os elementos.

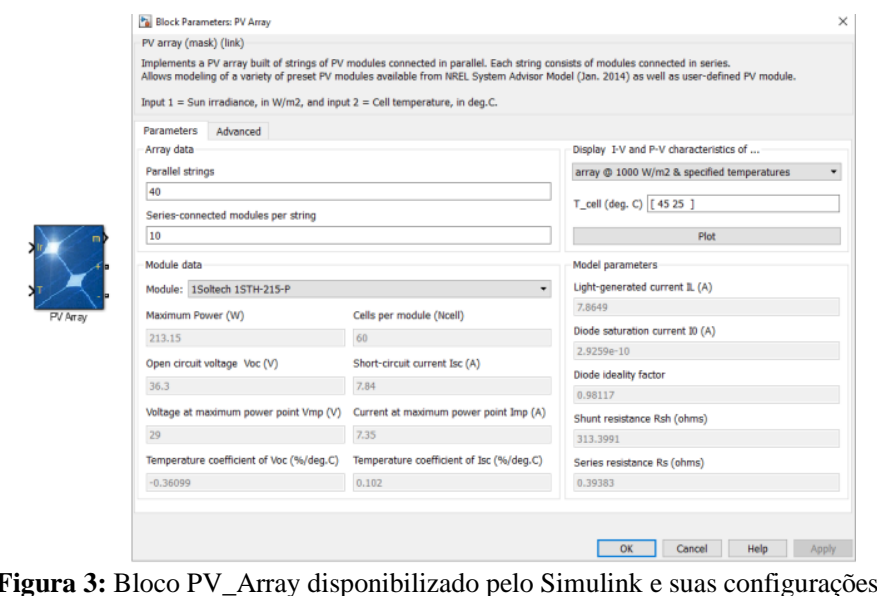

Como seguimento da pesquisa, levantou-se as informações solatimétricas do Brasil e foi averiguado que o mesmo possui taxas de irradiância solar mais elevadas que outros países que utilizam e incentivam mais abertamente a utilização da geração de 
energia solar, como a Alemanha. Segundo SOLAR (2018), o menor valor de irradiância mensurado no território brasileiro consegue ser mais elevado que o maior valor de irradiância medo em território alemão, como ilustram as Figuras 4 e 5.
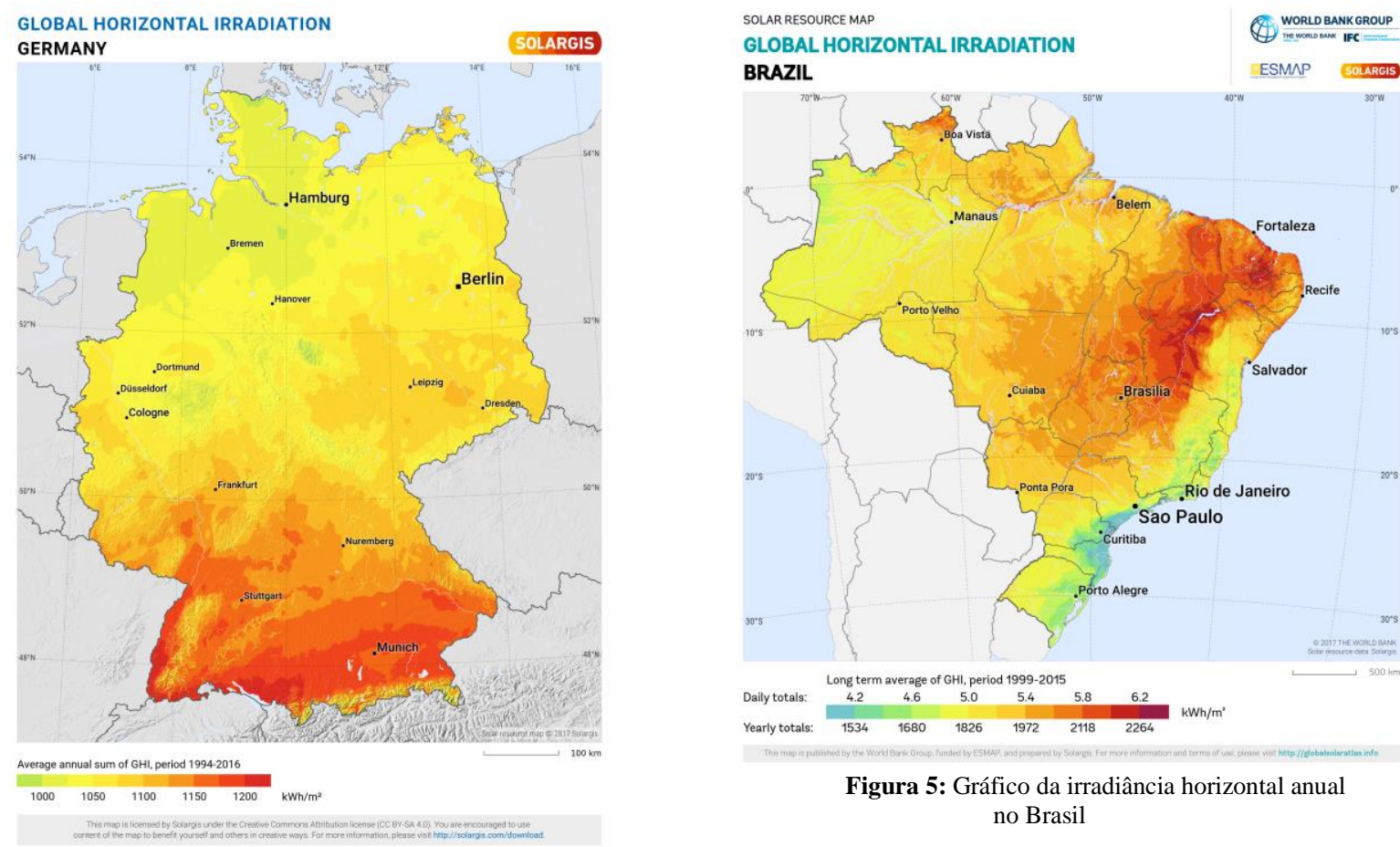

Figura 4: Gráfico da irradiância horizontal anual na Alemanha

A última etapa da pesquisa consistiu em verificar o funcionamento de métodos que propõe a extração máxima da potência do painel solar, REMY et al (2009) apresenta alguns métodos para encontrar o MPPT, dos métodos apresentados, um dos mais conhecidos e utilizados na literatura é o método Perturbação \& Observação, que consiste em criar uma perturbação no sistema e observar o seu comportamento, caso a perturbação seja positiva, simboliza que o painel solar ainda não atingiu o seu MPPT, caso contrário, a perturbação seja negativa, o painel já ultrapassou o seu MPPT, então o algoritmo deverá ajustar a tensão e/ou corrente de forma que na próxima observação o painel fique mais próximo de estar no seu MPPT.

\begin{tabular}{l|cccccccc}
\hline Tempo $(\mu \mathrm{s})$ & 0 & 5 & 10 & 15 & 20 & 25 & 30 & 35 \\
\hline Corrente & 0 & 0 & 0 & 0 & 0 & 0 & 0 & 0 \\
Tensão & 36,844 & 36,950 & 36,845 & 36,949 & 36,845 & 36,949 & 36,845 & 36,949 \\
$\begin{array}{l}\text { Duty } \\
\text { Cicle }\end{array}$ & 0,49998 & 0,49996 & 0,49994 & 0,49992 & 0,49994 & 0,49996 & 0,49998 & 0,5 \\
\hline
\end{tabular}

A Tabela 1 apresenta um recorte do resultado da simulação do algoritmo Perturbação e Observação, pode-se perceber que a cada instante, o algoritmo analisa o estado do painel e ajusta o seu sinal de controle (duty cicle) de forma a manter o painel solar funcionando o mais próximo possível do seu MPPT, garantindo assim a sua máxima eficiência possível. 


\section{CONSIDERAÇÕES FINAIS (ou Conclusão)}

A partir da modelagem matemática de um painel solar, pode-se estudar, observar e até mesmo prever o seu funcionamento, tarefas que são muito importantes para a implantação de sistemas de geração solar, notou-se que cada vez mais há a adesão nos trabalhos na literatura de modelagens utilizando as equações mais completas, que levam em consideração resistências em série e paralelo dos painéis. É possível também perceber que o modelo gerado a partir das equações consegue obter resultados muito significativos em comparação às informações do fabricante, assim como o elemento disponibilizado pelo Simscape Power Systems, dando ainda mais confiança para o modelo.

É discutido também, parte do potencial de produção de energia solar que o Brasil possui, chegando a ser superior a países desenvolvidos como a Alemanha, um sinal que temos muito desse recurso a ser aproveitado, reduzindo assim a necessidade da utilização de recursos hídricos como fonte primária de energia.

Por fim foi analisado o comportamento de um dos métodos existentes na literatura para se obter a otimização máxima do funcionamento de um painel solar, garantindo assim uma maior produção de energia e consequentemente um retorno do investimento mais rápido para o usuário.

\section{REFERÊNCIAS}

REMY, Ghislain et al. Review of mppt techniques for photovoltaic systems. Laboratoire de Génie Electrique de Paris (LGEP)/SPEE-Labs, Université Pierre et Marie Curie P, v. 6, 2009. Acesso em 06 abr. 2018

SOLAR resource maps and GIS data for 200+ countries. 2018. Disponível em: <https://solargis.com/maps-and-gis-data/download>. Acesso em: 10 jun. 2018.

VILLALVA, Marcelo Gradella et al. Conversor eletrônico de potência trifásico para sistema fotovoltaico conectado à rede elétrica. São Paulo. UNICAMP, 2010. Disponível em: <http://repositorio.unicamp.br/jspui/handle/REPOSIP/260742> Acesso em: 10 ago. 2017 